\title{
The Use of Health Care Services and Psychotropic Medication in a Community Sample of 9-Year-Old Schoolchildren with ADHD
}

Citation for published version (APA):

Tremmery, S., Buitelaar, J. K., Steyaert, J., Molenberghs, G., Feron, F. J. M., Kalff, A. C., Hurks, P. P. M., Hendriksen, J. G. M., Vles, J. S. H., \& Jolles, J. (2007). The Use of Health Care Services and Psychotropic Medication in a Community Sample of 9-Year-Old Schoolchildren with ADHD. European Child \& Adolescent Psychiatry, 16(5), 327-336. https://doi.org/10.1007/s00787-007-0604-5

Document status and date:

Published: 01/01/2007

DOI:

10.1007/s00787-007-0604-5

Document Version:

Publisher's PDF, also known as Version of record

Please check the document version of this publication:

- A submitted manuscript is the version of the article upon submission and before peer-review. There can be important differences between the submitted version and the official published version of record.

People interested in the research are advised to contact the author for the final version of the publication, or visit the DOI to the publisher's website.

- The final author version and the galley proof are versions of the publication after peer review.

- The final published version features the final layout of the paper including the volume, issue and page numbers.

Link to publication

\footnotetext{
General rights rights.

- You may freely distribute the URL identifying the publication in the public portal. please follow below link for the End User Agreement:

www.umlib.nl/taverne-license

Take down policy

If you believe that this document breaches copyright please contact us at:

repository@maastrichtuniversity.nl

providing details and we will investigate your claim.
}

Copyright and moral rights for the publications made accessible in the public portal are retained by the authors and/or other copyright owners and it is a condition of accessing publications that users recognise and abide by the legal requirements associated with these

- Users may download and print one copy of any publication from the public portal for the purpose of private study or research.

- You may not further distribute the material or use it for any profit-making activity or commercial gain

If the publication is distributed under the terms of Article 25fa of the Dutch Copyright Act, indicated by the "Taverne" license above, 


\author{
Sabine Tremmery \\ Jan K. Buitelaar \\ Jean Steyaert \\ Geert Molenberghs \\ Frans J.M. Feron \\ Ariane C. Kalff \\ Petra P.M. Hurks \\ Jos G.M. Hendriksen \\ Johan S.H. Vles \\ Jelle Jolles
}

\section{The use of health care services and psychotropic medication in a community sample of 9-year-old schoolchildren with ADHD}

Accepted: 11 January 2007

Published online: 16 July 2007

\author{
S. Tremmery $(\bowtie)$ \\ Dept. of Psychiatry \\ University Hospital \\ De Pintelaan 185 \\ 9000 Gent, Belgium \\ J.K. Buitelaar \\ Dept. of Psychiatry \\ Radboud University Nijmegen Medical \\ Centre, and \\ Karakter, Child and Adolescent Psychiatry \\ University Centre \\ Nijmegen, Netherlands \\ J. Steyaert \\ Dept. of Psychiatry \\ University of Leuven \\ Leuven, Belgium \\ G. Molenberghs \\ Dept. of Biostatistics \\ Hasselt University \\ Hasselt, Belgium \\ F.J.M. Feron \\ Youth Health Care Service \\ Municipal Health Center \\ Maastricht, Netherlands
}

Abstract Objective To examine the prevalence of the use of health care services and psychotropic medication within a community sample $(N=283)$ of 9year-old school children and, more specifically, to evaluate the use of prescribed stimulants. Methods Data from the second follow-up phase of the "Study of Attention Deficit Maastricht" (SAM) were analysed. Assessments at age 9 included a structured psychiatric interview with parents, behaviour and family situation questionnaire, IQ estimate and global assessment scale. Use of health care services and medication was obtained by the

A.C. Kalff · P.P.M. Hurks · J. Jolles Dept. of Psychiatry \& Neuropsychology Maastricht University Maastricht, Netherlands

J.G.M. Hendriksen

Gedragswetenschappelijke Dienst van Kempenhaeghe

Heezeam, Netherlands

J.S.H. Vles

Dept. of Neurology

Maastricht University Hospital

Maastricht, Netherlands
DICA-R and from the Youth Health Care records. Results About 190 children of the selected sample had at least one child psychiatric diagnosis, 26 (14\%) of them were clinically referred and $12(6 \%)$ received stimulants. Of the children with ADHD $(N=45), 10 / 45(22 \%)$ received stimulants. Conversely, 2 out of 12 children who were treated with stimulants did not meet full DSMIV diagnostic criteria, but were subthreshold ADHD cases. The treatment status was highly dependent on being clinically referred. Conclusion The major finding of our survey is a lack of referral to child mental health services, and associated underdiagnosis and undertreatment, particularly in children with ADHD. There is a critical need to translate and implement the diagnostic and treatment guidelines to clinical practice.

Key words ADHD health care services psychotropic medication epidemiology

\section{Introduction}

Attention Deficit Hyperactivity Disorder (ADHD) is a neuropsychiatric condition, characterized by enduring and pervasive symptoms of inattention, hyperac- tivity and impulsivity [28]. Stimulant medication (particularly methylphenidate) is a common and accepted form of treatment for ADHD. Methylphenidate has also proved to be very safe and generally well tolerated, and professional guidelines are available for 
determining optimal dosage levels and avoiding side effects $[6,7,28]$. However, the use of stimulant medication for the treatment of ADHD has not been without controversy. Concerns have been raised about overprescription of medication and potential abuse of stimulant medication [10,35]. The prescription of stimulant medication for children with ADHD has significantly increased in the last decade [19]. This increase is probably due to a number of factors, including an increase in public and clinical awareness and acceptance of ADHD as a disorder, a broadening of the diagnostic criteria for ADHD and an increase in the availability of ADHD-specific services, particularly pediatric and child psychiatric services [9]. Sceptics however, argue that the increase indicates an inappropriate use of stimulants. In the United States, the number of children who receive stimulants increased approximately 2.5 -fold in the first half of the 1990s [19]. The scarce research literature available outside the United States confirms this trend. A drug utilization study based on computerized pharmacy dispensing records was conducted from 1995 to 1999 for children aged 0 to 19 years in the north of the Netherlands also found a 2.5-fold increase [23]. In Australia, about 5300 children (age 017 years) started on stimulants for the first time in 2000 and this was 5 times the number in 1990 [20]. A German study showed that during the 1998-2000 period the number of methylphenidate prescriptions increased two and a half times [33]. These surveys were database driven and do not permit validation of the correctness of the diagnosis, thus precluding inferences about the appropriateness of the use of medication. Three studies have examined ADHD in an unbiased community-based design. In an American population of youth aged from 9 to 17 only 1 in 8 children with ADHD received stimulant treatment, but $50 \%$ of the children who were prescribed a stimulant did not meet diagnostic criteria for ADHD [10]. A similar result was found in an Australian population (aged 6-17) where $12.6 \%$ of the ADHD children received stimulants treatment and $23 \%$ of the children used stimulants without meeting the criteria for ADHD [21]. In the Great Smoky Mountains Study [3] 52.9\% of the ADHD or ADHD-NOS children (9-16 years old) received stimulant treatment, but $51.2 \%$ of the children who were prescribed a stimulant did not have any ADHD symptoms. These studies suggest a trend in the United States and Australia from the perspective of "evidence-based medicine" towards inappropriate use of stimulants, with undertreatment of children diagnosed with ADHD and overprescribing of stimulant medication in the group of children without ADHD. In Europe, no studies exist that examine the relationship between diagnostic correctness and the use of stimulants. A German study based on health insurance data gives little evidence for overtreatment because about two-thirds of the ADHD children did not receive drug therapy [24].

In this article we want to investigate the use of health care services and psychotropic medication in a community sample of 9-year-old schoolchildren, and, more specifically, the treatment status of ADHD children in a non-clinical Dutch population. This study is part of a large research program entitled "Study of Attention Disorders in Maastricht (SAM)". In a school-based prospective study the precursors of ADHD were investigated in children aged 5-6 [12, 14]. A multi-phase, screening-stratified sampling design was used [26] and the follow-up phase at age 9 was examined.

\section{Method}

\section{Subjects and procedure}

\section{Phase 1: Children enrolled at about 6 years of age}

The methodology has been reported in detail elsewhere [11]. This study was approved by the Ethics Committee of the Maastricht University (Fig. 1). All parents of a school-based population of 2,290 children were approached with regard to participation. All the children were enrolled in the kindergarten $(N=65)$ (year before the first grade of elementary school) in the Maastricht area, in the southern Netherlands. The parents of 1,317 (57.5\%) children (669 boys and 618 girls, age mean \pm SD $5.87 \pm 0.41$ year) agreed to participate and written informed consent was obtained for phases 1 and 2. Parents did not have to explain why they refused participation. No significant differences were observed between the 1,317 children who participated and the 973 children who did not in terms of age, gender and demographic factors [14]. Kroes et al. (1999) generalized the estimated prevalences of psychiatric disorders to an entire population and found no substantial differences. In the first stage the parents of all 1,317 children completed the Child Behaviour Checklist (CBCL) $[1,31]$ and a questionnaire on sociodemographic characteristics.

\section{Phase 2: First follow-up at 7 years of age}

On the basis of CBCL scores in phase 1, three groups of children (in total $N=452$ ) were selected for followup. The first, an externalizing high-risk group, consisted of 173 children with scores on the CBCL broadband externalizing scale above the 90th percentile $(T>63)$ and/or scores on the inattention scale of the CBCL above the 95th percentile $(T>67)$. The 
Fig. 1 Sampling design for the "Study of Attention Disorders in Maastricht"

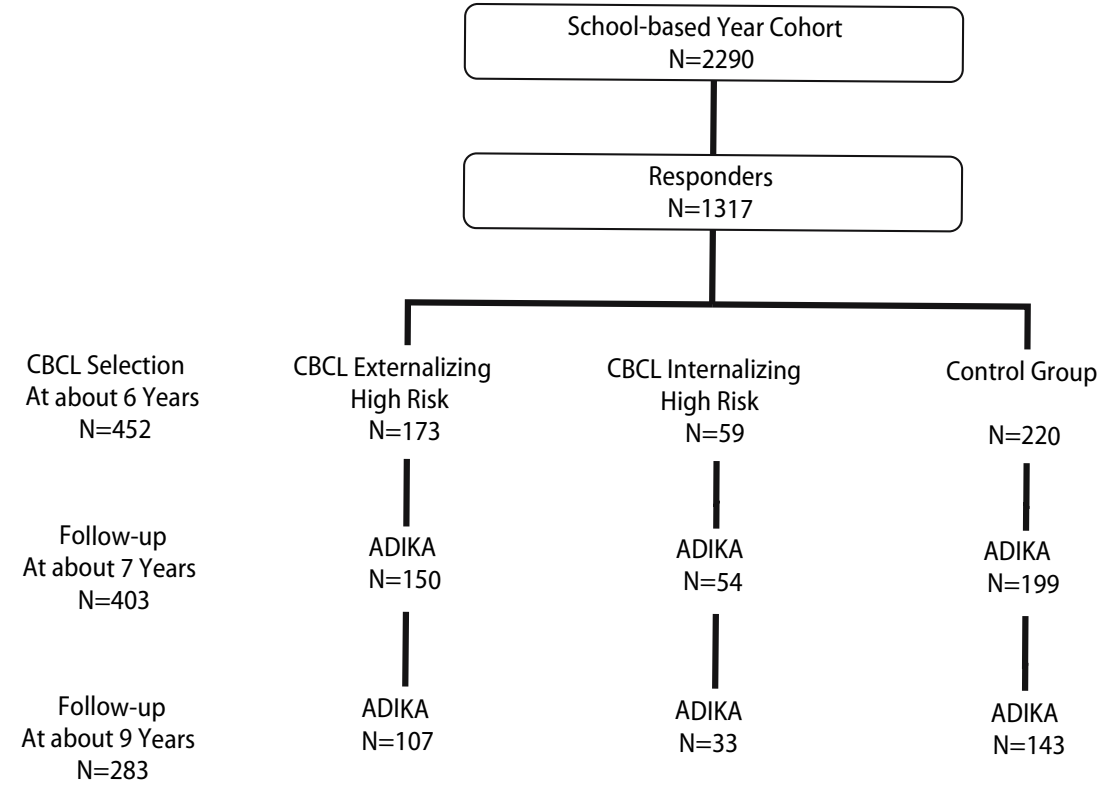

Scale (CGAS) and a cognitive functioning estimation of the child.

In total $283(63 \%$ of the selected sample) parents and children (163 boys and 120 girls, age $9.2 \pm 0.4$ year) took part. Among these were 107 (62\% from initial group) from the first group, 33 (56\% from initial group) from the second and 143 (65\% from initial group) controls. The 169 (36\%) non-participating children did not differ from the participating children in terms of psychiatric diagnosis at age 7 , age, gender and demographic factors.

\section{Measures}

The Child Behaviour Checklist (CBCL) and the Teacher Report Form (TRF) [2] were completed by parents and teachers when the children were 6 (CBCL), 7 (TRF) and 9 (TRF) years old respectively. The CBCL and TRF were computer scored, using appropriate age and gender norms for the Dutch population [5, 31].

Demographic information. When the children were 6 , the level of parental occupation was scored on a 7point scale, ranging from unskilled to graduate/professional, and was divided into three levels for the present study: low (1,2 and 3), middle (4 and 5) and high (6 and 7) [29]. Other demographic information included the parents' country of birth, family intactness (child living with one versus two parents), number of siblings and residential area (urban area of Maastricht versus surrounding villages).

The Diagnostic Interview for Children and Adolescents (DICA-R) [18] in its Dutch version (Amsterdam Diagnostisch Interview voor Kinderen-ADIKA) [13]

\section{Phase 3: Second follow-up at 9 years of age}

When the children were 9 the parents of the three groups of children were asked for written consent to continue participation, which included a structured psychiatric interview and an overall functioning evaluation using the Children's Global Assessment 
was used for structured psychiatric assessment of the children at 7 and 9 years of age. The DICA-R is based on the criteria of DSM-III-R (American Psychiatric Association, 1994) and was adapted to the criteria of DSM-IV (American Psychiatric Association, 1994) for diagnosing ADHD [30]. Although no reliability studies have been performed with the ADIKA, the DICA-R has been described recently as a useful measure in both research and clinical settings for providing reliable psychiatric information about children [29].

The DICA-R was administered to the parents of 7year-old children by three (a medical doctor, a psychologist and a health care worker) and of 9-year-old children by two (a child psychiatry trainee and a psychologist) different interviewers, who had received prior training. We chose to optimize reliability by intensive supervision of the interviewers by the child psychiatrist. To reach consensus and improve the reliability and validity of our diagnosis, the results were discussed weekly during an intensive supervision session of the interviewers by the research child psychiatrist (J.S.). Discrepancy in scoring was resolved by consensus. When questions arose, parents were reassessed for further clarification.

All interviewers were blind to the results of prior assessments. The DICA-R assesses symptoms of axis-I psychiatric disorders, such as disruptive, emotional, anxiety and elimination disorders, and their duration, impairment and possible consultation with health professionals. Diagnoses were generated by a computer algorithm that ignores the hierarchical DSM structure. For example, Oppositional Defiant Disorder (ODD) and Conduct Disorder (CD) could be diagnosed in the same patient.

The ADHD module of the Dutch DICA-R contains 10 questions about inattention and 11 about hyperactivity and impulsivity. Positive answers were used to compute the number of inattention symptoms (range 0-10) and the number of hyperactivity and impulsivity symptoms (range 0-11). The Dutch DICA-R includes 4 binary items on impairment: problems at home, problems at school, social problems and overall performance. An impairment sum score was derived (range 0-4) from these items. An ADHD diagnosis was generated when the DSM-IV criteria for ADHD were present with at least 6 hyperactive and impulsive symptoms and/or inattention symptoms, 2 positive scores on impairment and an age of onset before the age of 7 . When an ADHD diagnosis was reached, the ADHD subtype was based on a threshold score (min. 6) for the 2 symptom groups

Intelligence at age 9 was estimated with the Vocabulary and Block Design subtests of the WISC-R [15]. The children were tested at school by three psychology students and a child psychologist. They had been extensively trained in the assessment.

The Children's Global Assessment Scale (CGAS), a measure of overall severity of disturbance, is an adaptation of the Global Assessment Scale for adults [25]. The CGAS was completed at age 9 at the end of the interview by the interviewer. Information obtained during the interview was accomplished with a non-structured interview about the functioning of the child at home, at school, with friends and during spare time. To optimize the reliability of the scoring, the results were discussed weekly during an intensive supervision session of the interviewers by the child psychiatrist (J.S.).

Information on the treatment or services was collected in two different ways. First the DICA-R contains a question about services used and medication taken for each positively scored diagnosis. Secondly, information was collected by the Youth Health Care (YHC) Service. This national organization is responsible for performing a periodic systematic health examination for all children in the region. The response rate is $98 \%$. School doctors perform this examination and they are allowed, by law, to use the medical information gained anonymously for epidemiological research purposes. The information obtained by the interview was in all cases similar to the YHC files. Only YHC information was available for the children not reaching a threshold diagnosis.

Subjective Family Burden and Assessment of Educational Situation was measured by a Dutch questionnaire, the Nijmegen Family Situation Questionnaire (NVOS). The reliability and validity are good to excellent [34]. The Subjective Family Burden exists of 46 items resulting in 8 categories: acceptance of the educational situation, coping capacity, having problems with the child, wanting a different educational situation, child is burden, being on one's own in the educational situation, enjoying education and having good contact with the child. Each item is scored from 1 to 5 , with a low score indicating a positive response and a high score indicating a problematic situation. The score for each category is the average of the corresponding items. The norm score for a clinically referred population varies between 2.13 and $2.68(2.4 \pm 0.3)$ for the different categories and for a control group between 1.4 and $2.01(1.7 \pm 0.3)$. As regards the educational situation, parents can make a choice out of 8 descriptions of the current educational situation, with the highest score indicating that there are no problems and no need for educational support, and the lowest score indicating that there are severe problems, parents are desperate and urgent help is necessary. The norm score for a clinically referred population is 4.07 and for a control group 2.07. 
Table 1 Child and family demographic characteristics according to the ADIKA diagnostic status

\begin{tabular}{|c|c|c|c|c|c|c|c|}
\hline & \multicolumn{2}{|c|}{$\begin{array}{l}\text { ADHD } \\
(n=45)\end{array}$} & \multicolumn{2}{|c|}{$\begin{array}{l}\text { Other diagnosis } \\
(n=145)\end{array}$} & \multicolumn{2}{|c|}{$\begin{array}{l}\text { No diagnosis } \\
(n=93)\end{array}$} & \multirow[b]{2}{*}{ Kruskal-Wallis } \\
\hline & Mean & s.d. & Mean & s.d. & mean & s.d. & \\
\hline Age at baseline & 6.1 & $(0.5)$ & $5.9^{\mathrm{b}}$ & $(0.4)$ & $5.8^{\mathrm{b}}$ & $(0.4)$ & 0.03 \\
\hline \multicolumn{8}{|l|}{ CBCL at 6 years } \\
\hline Total & 66.4 & (9.4) & $56.5^{\mathrm{b}}$ & (11.7) & $48.6^{\mathrm{bc}}$ & (11.5) & $<0.0001$ \\
\hline Internalizing & 59.1 & (9.4) & $55.7^{\mathrm{b}}$ & (11.3) & $48.1^{\mathrm{bc}}$ & (10.1) & $<0.0001$ \\
\hline Externalizing & 65.4 & (10.9) & $56.4^{\mathrm{b}}$ & (11.7) & $49.9^{\mathrm{bc}}$ & (11.0) & $<0.0001$ \\
\hline \multirow[t]{2}{*}{ Inattention Scale } & 65.5 & (9.4) & $56.1^{\mathrm{b}}$ & (6.9) & $53.2^{\mathrm{bc}}$ & (5.3) & $<0.0001$ \\
\hline & $n$ & $\%$ & $n$ & $\%$ & $n$ & $\%$ & Chi-square \\
\hline Gender boys & 35 & (77.8) & $48^{\mathrm{b}}$ & $(57.9)$ & $45^{\mathrm{b}}$ & (48.4) & .005 \\
\hline Urban & 31 & (68.9) & 98 & (67.6) & 52 & (55.9) & .14 \\
\hline Intact family & 36 & (80) & 114 & (78.6) & $87^{\text {bc }}$ & (93.5) & .007 \\
\hline Immigrant parents & 4 & (9.3) & 18 & (12.6) & 11 & (12.1) & .84 \\
\hline Education parents ${ }^{\mathrm{a}}$ & & & & & & & .005 \\
\hline Low & 27 & (60) & 64 & (45.4) & $28^{\mathrm{b}}$ & (30.1) & \\
\hline Average & 12 & (26.7) & 34 & (24.1) & $27^{\mathrm{b}}$ & $(29.0)$ & \\
\hline High & 6 & (13.3) & 43 & (30.5) & $38^{\mathrm{b}}$ & (40.9) & \\
\hline
\end{tabular}

${ }^{\mathrm{a}} 4$ missing in the No diagnosis group

${ }^{\mathrm{b}}$ Significantly different at .05 from high risk externalizing

'Significantly different at .05 from high risk internalizing

\section{Statistical procedures}

Explorative analysis was performed for all variables using bivariate and multivariate tests. The Pearson $\chi^{2}$ test $\left(\chi^{2}\right)$ and the Fisher exact two-sided test (FE) were used for the nominal variables. The Wilcoxon rank sum test $(W)$ and Kruskal-Wallis test (KW) were used for continuous variables that were not normally distributed. Logistic regression was used to obtain odds ratios with the Wald confidence limits (OR 95\% CI). Because analyses were exploratory rather than hypothesis-driven we did not correct for multiple testing. We used 0.05 as threshold of statistical significance.

\section{Results}

\section{Child and family demographic characteristics at age 9 as a function of the DICA-R diagnostic status}

In Table 1 we present the child and family demographic characteristics for the 283 participating children at age 9 as a function of the DICA-R diagnostic status: ADHD $(n=45)$, other diagnosis $(n=145)$ and no diagnosis $(n=93)$. The other diagnosis includes other disruptive behaviour disorders, mood disorder, elimination disorder and pervasive developmental disorder. The criteria for simple phobia are not age specific and result in an overestimation of anxiety disorder at this age [14], so more than two anxiety disorders had to be present. Of the children interviewed, $14.9 \%$ were regarded as having DSM-IV ADHD. As we used a design that oversampled children with ADHD because of selection based upon CBCL externalizing group, this percentage is not representative for the general population. At age 7 Kroes et al. (2001) found an ADHD prevalence of $3.8 \%$ for the entire $(N=2290)$ population.

The age at baseline was about 6 , with the ADHD group containing slightly older children than the 2 other groups (KW $7.0 \mathrm{df}=2, P=0.03$ ). Boys were over represented in the ADHD group (77.8\% versus $57.9 \%$ in the other diagnosis group and versus $48.4 \%$ in the no diagnosis group, $\chi^{2} 10.7 \mathrm{df}=2, P=0.005$ ). Two family demographic characteristics distinguish the different groups. The first, intactness of the family was overrepresented in the no diagnosis group (93.5 vs. $80 \%$ in the ADHD group and $78.6 \%$ in the no other diagnosis group, $\left.\chi^{2}=9.8 \mathrm{df}=2, P=0.007\right)$. Secondly, parents of the no diagnosis group tend to be more highly qualified than parents of the other groups $(\mathrm{KW}=14.7 \mathrm{df}=4, P=0.005)$. The other sociodemographic variables did not distinguish between the three groups.

\section{Use of services}

In Table 2 we present data on the major types of services provided for the 283 participating children at age 9 as a function of the DICA-R diagnostic status: ADHD, other diagnosis and no diagnosis. Only 30/283 $(10.6 \%)$ of the study population had ever been clini- 
Table 2 Numbers of children receiving types of services by ADIKA diagnostic status

\begin{tabular}{|c|c|c|c|c|c|c|c|c|}
\hline & \multicolumn{2}{|c|}{$\begin{array}{l}\text { ADHD } \\
(n=45)\end{array}$} & \multicolumn{2}{|c|}{$\begin{array}{l}\text { Other diagnosis } \\
(n=145)\end{array}$} & \multicolumn{2}{|c|}{$\begin{array}{l}\text { No diagnosis } \\
(n=93)\end{array}$} & \multicolumn{2}{|c|}{$\begin{array}{l}\text { Total } \\
(n=283)\end{array}$} \\
\hline & $n$ & $\%$ & $n$ & $\%$ & $n$ & $\%$ & $n$ & $\%$ \\
\hline Clinically Referred & 16 & (35.6) & 10 & (6.9) & 4 & (4.3) & 30 & (10.6) \\
\hline Stimulants & 10 & (22.2) & 1 & $(0.7)$ & 1 & (1.1) & 12 & $(4.2)$ \\
\hline Other medication & 0 & (0) & 1 & (0.7) & 0 & (0) & 1 & $(0.3)$ \\
\hline School services & 5 & (11.1) & 10 & (6.9) & 6 & (6.4) & 21 & (7.4) \\
\hline Psychosocial treatment & 6 & (13.3) & 8 & (5.5) & 2 & (2.1) & 16 & (5.6) \\
\hline
\end{tabular}

cally referred for psychosocial or behavioural problems. This referral could be to a paediatrician $(n=1)$, child neurologist $(n=8)$, or a child psychiatrist $(n=22)$. Some children were referred to more than one medical doctor. Children were 7.1 (95\% CI 2.917.1) times more likely to be referred for ADHD behaviour $(n=16$ or $5.6 \%)$ than for other psychopathology $(n=10$ or $3.5 \%)$ (FE, $P=0.03)$. This trend was not present for other types of services such as school services or psychosocial treatment. In the ADHD group 5 children versus 10 in the other psychopathology group received school services (FE, $P=0.15)$ and 6 children versus $8(\mathrm{FE}, P=0.06)$ received psychosocial treatment.

\section{Use of medication}

Methylphenidate was the only prescribed stimulant treatment in this cohort. At age 7, none of the children received stimulant medication. At age 9, 12 children or $4.2 \%$ of the follow-up study population receive stimulant medication. Medication was initiated in 11 children after clinical referral, and only one child received medication after contacting the general practitioner (GP). Ten children had a DICA-R diagnosis of ADHD, 1 child with an emotional disorder and one child with no diagnosis at all. Two children with a positive ADHD diagnosis received both therapies (medication and psychosocial treatment).

Thus, 2 out of $12(16.6 \%)$ of the children on stimulants did not meet full diagnostic criteria for ADHD. This group is too small to draw strong conclusions, but some individual descriptions can be made. Both children have subthreshold or borderline ADHD. They have threshold ADHD symptom scores but low impairment scores. They have poor results on the WISC-R but were going to a normal school, had average to highly educated parents, and the teacher scored average to high on the TRF.

Within the ADHD group 30/45 (66.7\%) of the children did not receive any kind of therapy, 10 $(22.2 \%)$ received monotherapy and $5(11.1 \%)$ received combined therapy. Looking at the different kinds of therapy, $10(22.2 \%)$ received stimulant medication, 5 (11.1\%) special school services and 6 (13.3\%) psy- chosocial treatment. Only one child, diagnosed with autism, received a non-stimulant medication (pipamperone).

The average dose of methylphenidate was about $22.5 \pm 8.6 \mathrm{mg} /$ day and there was no dependence on the ADHD diagnostic status.

To evaluate the rationale for stimulation treatment, two different subgroups were formed. The first group included the children with ADHD who were treated with stimulants $(n=10)$, the second group the children with ADHD without stimulant treatment $(n=35)$.

\section{Influence of Demographics, ADHD Characteristics, Comorbidity and Educational Situation on Stimulant Treatment Status}

As expected, the main difference between these two groups was the percentage of children clinically referred ( 90 vs. $20 \%$, FE, $P<0.001$ ) (Table 3 ).

Furthermore, the ADHD children on stimulants, compared with those without stimulant use, had higher total scores on the TRF at age 7, (mean \pm SD $62.0 \pm 12.6$, versus $56.2 \pm 8.4, W, P=0.3$ ), had more inattentive symptoms of ADHD as obtained by DICA$\mathrm{R}(8.2 \pm 1.1$ vs. $7.1 \pm 1.8, W, P=0.05)$, had more frequent comorbid conduct disorder (40 vs. $11.4 \%$, Fisher exact test, $P=0.06$ ) and had less frequent comorbid oppositional defiant disorder (20 vs. $60 \%, F$, $P=0.03)$. No differences between the two groups were found in regard to gender, residential area, family intactness, parental education, prorated scores of the WISC, CBCL scores at age 6, CGAS, the distribution of ADHD subtypes, the ADHD impairment score and comorbidity with anxiety and mood disorders.

We also explored whether ADHD children treated with stimulants differed from those without stimulants in terms of subjective family burden, educational situation and need for health care services. Both ADHD groups had high scores for subjective family burden, which were consistent with the norm scores for clinically referred populations (between $1.6 \pm 0.4$ and $3.2 \pm 0.8$ for the different categories). Similar results were obtained for the educational situation, where both ADHD groups scored within the clinical 
Table 3 Characteristics among children with/without stimulant treatment

\begin{tabular}{|c|c|c|c|c|c|}
\hline & \multicolumn{2}{|c|}{$\begin{array}{l}\text { ADHD + Stimulant+ } \\
(n=10)\end{array}$} & \multicolumn{2}{|c|}{$\begin{array}{l}\text { ADHD + Stimulant- } \\
(n=35)\end{array}$} & \multirow[b]{2}{*}{ Fisher exact } \\
\hline & $n$ & $\%$ & $n$ & $\%$ & \\
\hline Gender boys & 10 & $(100)$ & 25 & (71.4) & 0.08 \\
\hline Clinically referred & 9 & (90) & 7 & (20) & 0.001 \\
\hline \multicolumn{6}{|l|}{ Comorbidity } \\
\hline ODD & 2 & (20) & 21 & (60) & 0.03 \\
\hline$C D$ & 4 & (40) & 4 & (11.4) & 0.06 \\
\hline Mood disorder & 5 & (50) & 24 & (68.6) & 0.4 \\
\hline Anxiety disorder $>2$ & 4 & (40) & 11 & (31.4) & 0.7 \\
\hline \multirow[t]{2}{*}{ Enuresis } & 3 & (30) & 8 & (22.9) & 0.7 \\
\hline & Mean & s.d. & Mean & s.d. & Wilcoxon \\
\hline \multicolumn{6}{|l|}{ TRF at age 7} \\
\hline Total & 62.0 & (12.6) & 56.2 & (8.4) & 0.03 \\
\hline Externalizing & 63.0 & (11.6) & 55.7 & (9.9) & 0.08 \\
\hline Internalizing & 55.8 & (12.7) & 50.8 & $(10.4)$ & 0.3 \\
\hline Inattention scale & 63.7 & (10.1) & 57.0 & (6.6) & 0.09 \\
\hline \multicolumn{6}{|l|}{ ADHD criteria } \\
\hline Inattentive items & 8.2 & $(1.1)$ & 7.1 & (1.8) & 0.05 \\
\hline Hyperactive \& impulsive items & 8.5 & (2.7) & 6.8 & (3.1) & 0.09 \\
\hline Impairment & 3 & $(0.8)$ & 2.9 & $(0.8)$ & 0.8 \\
\hline Age of onset & 3.1 & (2.2) & 2.8 & (2.0) & 0.9 \\
\hline CGAS & 56.2 & $(6.5)$ & 58.1 & (7.6) & 0.7 \\
\hline
\end{tabular}

range $(3.7 \pm 1.2$ vs. $3.6 \pm 1.8)$. However, the subjective family burden and assessment of the educational situation did not differ between ADHD children with or without stimulant treatment.

\section{Discussion}

To the best of our knowledge, this survey is the first European study examining the relationship between ADHD status and the clinical referral and treatment status including the use of psychotropic medication in a non-clinical sample of ADHD children.

Since the start of the discussion about the question of over versus undertreatment of ADHD [10], sceptics have argued that only community-based epidemiological surveys within a well-defined sampling frame and rigorous diagnostic procedures can yield meaningful estimates of treated and untreated prevalence rates of ADHD. These diagnostic procedures must include the information of different informants so that the presence of the ADHD symptoms can be evaluated in more than one setting. In this project, we have tried to achieve this by using a semi-structured interview of the parent with specific questions about the onset of the symptoms and the impairment in different settings such as home, school, friends and overall functioning. The CBCL and TRF behaviour questionnaires were completed by the parents and teachers at different ages, together with specific child and family characteristics such as IQ, CGAS, subjective family burden and assessment of the educational situation. As such, we were able to validate the DICA-R based diagnoses at subgroup level by questionnaire data completed by parents and teachers. Despite the methodological limitation in respect of generalizing our results to an entire population, the relation between ADHD status and mental health support generates some interesting hypotheses, which we will discuss further in this section.

We conducted our survey in a cohort of schoolchildren all of the same age. At the time of the data collection (1999-2000) the children were about 9-10 years old, when ADHD is most prevalent [17, 27]. Another important issue is the short study's sampling period ( 8 months) and the fact that information on the prescription of medication was attached to the period of 12 months just before the interview. Since we did not want to rely just on the parents for the information about prescribing psychotropic medication, information was also collected by Youth Health Care (YHC) Service. In this way additional information was collected with exact start and end dates of medication, together with the doses and the prescriber.

Our study shows a discrepancy between DICA-R diagnosis and the use of medical health care services. Only $13.7 \%$ of the children with an eventual child psychiatric diagnosis had been clinically referred in the 12 months before the interview. This figure was higher $(35.6 \%)$ for the ADHD group. It would be 
interesting to investigate the factors influencing the referral and treatment status. Several studies have been done to investigate the concordance between the psychological diagnosis by a general practitioner (GP) and parent reports of psychological problems. A London study [22] showed that only a third of parents of 5 to 11 year olds who had concerns expressed them during the consultation. In a general population sample of 2,449 Dutch children and adolescents (417 years old) [36] the concordance between psychological diagnoses by the GP and parent, teacher and adolescent reports of psychological problems was limited. Strong recommendations were made to increase GP identification of child psychological problems and enhance access to care for those in need. Our results support these recommendations, but the study design limits the generalization.

At the time of the data collection (1999-2000) the dramatic increase in prescribing methylphenidate in the Netherlands had occurred [23], but the use of psychotropic medication within an at-risk population still remains low. Only $4.2 \%$ of our follow-up study population used stimulants-all methylphenidate-and only one child $(0.3 \%)$ used other psychotropic medication. Of the children with an ADHD diagnosis, only $22.2 \%$ received stimulants.

Because of the different design of epidemiological studies on the use of stimulants, it is difficult to compare our results with other studies. Important differences are the age of the child under study, the use of DSM IV, the short study's sampling period and the time of collecting the data (1999-2000). Nevertheless, our results are congruent with the findings of Jensen (1999) in an American population and Sawyer (2002) in an Australian population with about 1 in 8 children with ADHD receiving medication. In our study, we found few arguments for the group with stimulant treatment being less impaired than the group without stimulant treatment. Parents of both groups have a serious need for health care services. Both impairment and CGAS scores indicated serious impairment in all the ADHD children. Possible protective factors such as sociodemographic or educational characteristics or absence of comorbidity were found unable to explain the treatment versus non treatment status of the ADHD children. They support the idea that undertreatment of ADHD is the predominant problem.

A next and related issue is whether the treatment offered is adequate. The average dose of methylphenidate in our study was about $22.5 \pm 8.6 \mathrm{mg} /$ day. This dose is comparable to the average dose at baseline in the community part ( $23 \mathrm{mg}$ daily) of the MTA study [16]. The MTA study showed that the titration protocol for optimal treatment effect of methylphenidate resulted in higher doses [32]. We have no information on the effect of the medication in our sample, but it could be interesting to evaluate the effect of the protocol in this population. Extrapolating from the MTA study, our data suggest that the prescribed dosages of methylphenidate were suboptimal.

Factors influencing the medication status in the present study were the number of inattentive symptoms and the absence of comorbidity with ODD. The groups were too small to investigate the distribution of subtypes of ADHD. The subjective family burden and the educational situation seemed to have no influence on this result, but the recognition of the problems by the teacher was highly significant. The treated and untreated ADHD group experienced the same burden and both achieved the norm score for a clinical population, indicating that medication was necessary and undertreatment was present also for the untreated ADHD group. Questions arise as to whether the subjective family burden and the educational situation are good measures for the need for psychopharmacological treatment. One study examined ADHD and parental psychological distress with respect to the medication status of children with ADHD [8]. The introduction of medication status in the multiple regression analyses did not significantly influence parental stress. This suggests that subjective family burden may be associated more with "learned helplessness" than with the child's behaviour [8].

The most important factor influencing the medication status was being clinically referred. Almost all the children with stimulant treatment were referred compared with only $20 \%$ of the ADHD children without stimulant treatment. This correlation could be expected because referral is necessary to obtain medication. ADHD behaviour was more related to clinical referral than other psychopathology, but other patterns determining the referral status remain unclear. Further work is needed on parental and child behaviour characteristics before any conclusion can be drawn. We will focus on this in a future report.

Two of the 12 children receiving stimulants (i.e. $16.6 \%$ ) did not meet the full diagnostic criteria for ADHD. They had threshold ADHD symptoms on at least one symptom cluster but without impairment. Of these, one child was diagnosed with an emotional disorder and one child had no diagnosis at all. We have reason to believe that the use of stimulants in these cases is not totally inappropriate. Another consideration is the effect of treatment resulting in the disappearance of the symptoms and underscoring on the DICA. Angold (2000) however investigated this topic and concluded that low symptom score cannot be accounted for by the curative effect.

The methods in this study design were well worked out and a 2-stage screening design was used. Twostage designs frequently result in wide confidence intervals, so that results have to be interpreted pru- 
dently. The data did not suggest selective attrition and the drop-out rate was about similar to that of a comparable study [4]. Nonetheless, because of the 2stage screening design it is difficult to estimate to what extent these results can be generalized to an entire population. The drop-out rate could be influenced by the treatment status and biases the results in both ways. Furthermore, although the children were recruited from a large primary school population $(N=1317)$, it should be acknowledged that the prevalence of ADHD diagnoses would have been larger if children from special schools for primary education had been included. These results should therefore be replicated in other samples.

The recent findings of the MTA study and the European Clinical Guidelines for hyperkinetic disorder indicate that for pervasive and severe disabling ADHD stimulant medication is more powerful than behaviour treatment alone. With respect to this recommendation, the availability of medication for ADHD children whose problems are severe should be a major concern. Based on our survey, we have few reasons to conclude that overtreatment with stimulants is a major problem in this region of the Netherlands. Undertreatment and low rates of clinical referral to child mental health services of children who are impaired by their ADHD symptoms seems to be one of the major findings of our survey. Research is needed to elucidate the most common pathways leading to children's referral, diagnosis and treatment and to evaluate the impact on this process by variables such as parental perception of impairment, social and academic expectations, schools' attitudes, clinician characteristics, health insurance and availability of alternative services.

Acknowledgements This research was supported by Maastricht University Hospital, Zorg Onderzoek Nederland (Netherlands Organization for Health Research and Development; formally the Prevention Foundation of the Netherlands), the Brain \& Behaviour Research Institute of Maastricht University and the Clemens Foundation of the Netherlands.

\section{References}

1. Achenbach T (ed) (1991) Manual for the child behavior checklist $4-18$ and 1991 profile. University of Vermont Department of Psychiatry, Burlington

2. Achenbach T (ed) (1991) Manual for the teacher's report form and 1991 profile. University of Vermont Department of Psychiatry, Burlington

3. Angold A, Erkanli A, Egger H-L, Costello E-J (2000) Stimulant treatment for children: a community perspective. J Am Acad Child and Adolesc Psychiatry 39:975-984

4. August G-J, Braswell L, Thuras P (1998) Diagnostic stability of ADHD in a community sample of school-age children screened for disruptive behavior. J Abnorm Child Psychol 26:345-356

5. De Groot A, Koot H, Verhulst F (1996) Cross-cultural generalizability of the Youth Self-Report and Teacher's Report Form cross informant syndromes. J Abnorm Child Psychol 24:651-664

6. Goldman L-S, Genel M, Bezman R-J, Slanetz P-J (1998) Diagnosis and treatment of attention-deficit/hyperactivity disorder in children and adolescents. JAMA: J Am Med Assoc 279:1100-1107

7. Greenhill L-L, Halperin J-M, Abikof $\mathrm{H}$ (1999) Stimulant medications. J Am Acad Child Adolesc Psychiatry 38:503512
8. Harrison C, Sofronoff K (2002) ADHD and parental psychological distress: role of demographics, child behavioral characteristics, and parental cognitions. J Am Acad Child Adolesc Psychiatry 41:703-711

9. Hoagwood K, Kelleher KJ, Feil M, Comer DM (2000) Treatment services for children with ADHD: a national perspective. J Am Acad Child Adolesc Psychiatry 39:198-206

10. Jensen PS, Kettle L, Roper MT, Sloan MT, Dulcan MK, Hoven C, Bird HR, Bauermeister JJ, Payne JD (1999) Are stimulants overprescribed? Treatment of ADHD in four U.S. communities. J Am Acad Child Adolesc Psychiatry 38:797-804

11. Kalff AC, Kroes M, Vles JS, Bosma H, Feron FJ, Hendriksen JG, Steyaert J, van Zeben TM, Crolla IF, Jolles J (2001) Factors affecting the relation between parental education as well as occupation and problem behaviour in Dutch 5- to 6-year-old children. Soc Psychiatry Psychiatr Epidemiol 36:324-331

12. Kalff AC, Kroes M, Vles JS, Hendriksen JG, Feron FJ, Steyaert J, van Zeben TM, Jolles J, van Os J (2001) Neighbourhood level and individual level SES effects on child problem behaviour: a multilevel analysis. J Epidemiol Community Health 55:246-250
13. Kortenbout van der Sluijs M, Levita D, Manen R, Defares P (1993) In: ADIKA, Amsterdams Diagnostisch Interview voor Kinderen en Adolescenten. Swetz and Zeitlinger, Lisse

14. Kroes M, Kalff AC, Kessels AG, Steyaert J, Feron FJ, van Someren AJ, Hurks PP, Hendriksen JG, van Zeben TM, Rozendaal N, Crolla IF, Troost J, Jolles J, Vles JS (2001) Child psychiatric diagnoses in a population of Dutch schoolchildren aged 6 to 8 years. J Am Acad Child Adolesc Psychiatry 40:1401-1409

15. Lezak MD (1995) Neuropsychological Assessment. Oxford University Press, Oxford

16. Pelham W-E Jr (1999) The NIMH multimodal treatment study for attention-deficit hyperactivity disorder: just say yes to drugs alone? Can J Psychiatry 44:981-990

17. Pineda D-A, Ardila A, Rosselli M, Arias B-E, Henao G-C, Gomez L-F, Mejia S-E, Miranda M-L (1999) Prevalence of attention-deficit/hyperactivity disorder symptoms in 4- to 17-year-old children in the general population. J Abnorm Child Psychol 27:455-462

18. Reich W, Shayla JJ, Taibleson C (1992) The diagnostic interview for children and adolescents-Revised (DICA-R) (structured psychiatric interview). Washington University, St Louis, MO 
19. Safer DJ, Zito JM, Fine EM (1996) Increased methylphenidate usage for attention deficit disorder in the 1990s. Pediatrics 98:1084-1088

20. Salmelainen P (2002) Trends in the prescribing of stimulant medication for the treatment of attention deficit hyperactivity disorder in children and adolescents in New South Wales. N S W. Public Health Bull 13(Suppl S-1):165

21. Sawyer MG, Rey JM, Graetz BW, Clark JJ, Baghurst PA (2002) Use of medication by young people with attentiondeficit/hyperactivity disorder. Med J Aust 177:21-25

22. Sayal K, Taylor E (2004) Detection of child mental health disorders by general practitioners. $\mathrm{Br} J$ Gen Pract 54:348-352

23. Schirm E, Tobi H, Zito JM, de Jong-van den Berg LT (2001) Psychotropic medication in children: a study from the Netherlands. Pediatrics 108:E25

24. Schubert I, Köster I, Adam C, Ihle P, Döpfner M, Lehmkuhl G (2003) Psychotropic drugs for children with the claims diagnosis "attention deficit/ hyperkinetic disorder". A drug utilisation study of outpatient care with person-related data of the Statutory Health Insurance (Versichertenstichprobe AOK Hessen/ KV Hessen, 1998-2001) Zeitschrift für Gesundheitswissenschaften 11:306-324
25. Shaffer D, Gould M-S, Brasic J, Ambrosini P, Fisher P, Bird H, Aluwahlia S (1983) A children's global assessment scale (CGAS). Arch Gen Psychiatry 40:1228-1231

26. Shrout P, Skodol A, Dohrenwend B (1986) A two-stage approach for case identification and diagnosis: first-stage instruments. Guildford Press, New York

27. Szatmari P, Offord D-R, Boyle M-H (1989) Ontario child health study: prevalence of attention deficit disorder with hyperactivity. J Child Psychol Psychiatry 30:219-230

28. Taylor E, Dopfner M, Sergeant J, Asherson P, Banaschewski T, Buitelaar J, Coghill D, Danckaerts M, Rothenberger A, Sonuga-Barke E, Steinhausen HC, Zuddas A (2004) European clinical guidelines for hyperkinetic disorder-first upgrade. Eur Child Adolesc Psychiatry 13:I7-30

29. van den Brandt P-A, Goldbohm R-A, van 't Veer P, Volovics A, Hermus R-J, Sturmans F (1990) A large-scale prospective cohort study on diet and cancer in the Netherlands. J Clin Epidemiol 43:285-295

30. Van Grimbergen I, Célestin-Westreich S, Ponjaert-Kristofferson I (1999) Validering van ADIKA-IV(deel externaliserend gedrag) bij een klinische populatie kinderen tussen 6 en 18 jaar. In: Garant (ed) De kinderschoenen ontgroeid? Tweede Vlaams Congres Kinder- en jeugdpsychiatrie en -psychotherapie, Leuven, pp 76
31. Verhulst F, Van der Ende J, Koot $\mathrm{H}$ (1996) In: Handleiding voor de CBCL Erasmus University/Departement of Child and Adolescent Psychiatry, Sophia Children's Hospital, Rotterdam

32. Vitiello B, Severe JB, Greenhill LL, Arnold LE, Abikoff HB, Bukstein OG, Elliott GR, Hechtman L, Jensen PS, Hinshaw SP, March JS, Newcorn JH, Swanson JM, Cantwell DP, Davies M, Clevenger $\mathrm{W}, \mathrm{Wu} \mathrm{M}$, Conners $\mathrm{CK}$, Hoza B, Kraemer HC, Wells K, Wigal T, Elliott G, Newcorn J, Pelham WE (2001) Methylphenidate dosage for children with ADHD over time under controlled conditions: lessons from the MTA. J Am Acad Child Adolesc Psychiatry 40:188-196

33. von Ferber L, Lehmkuhl G, Köster I, Döpfner M, Schubert I, Frölich J, Ihle P (2003) Methylphenidate Usage in Germany. Deutsches Ärzteblatt 100:A41A46

34. Wels PMA, Robbroeckx LMH (1996) Manual of Nijmeegse questionnaire for educational situation. Swets and Zeitlinger BV, Lisse

35. Wolraich M-L (1999) Attention deficit hyperactivity disorder: the most studied and yet most controversial diagnosis. Mental Retard Dev Disabil Res Rev 5:163-168

36. Zwaanswijk M, Verhaak PF, van der Ende J, Bensing JM, Verhulst FC (2005) Consultation for and identification of child and adolescent psychological problems in Dutch general practice. Fam Prac 17:17 